\title{
Assessment of Marine Rescue Abilities Based on ISM and AHP as well as Fuzzy Evaluation
}

\author{
Mingzhang Chen ${ }^{1, \text { a }}$, Jingxian Liu ${ }^{2, b}$, Weihao Ma ${ }^{3, \mathrm{c}}$, Zhaozhang $\mathrm{Li}^{4, \mathrm{~d}}$, \\ Zehan Zhang ${ }^{5, e}$ \\ ${ }^{1}$ Department of shipping, Wuhan university of technology, Wuhan, 430063, China \\ 2 Department of shipping, Wuhan university of technology, Wuhan, 430063, China \\ ${ }^{3}$ Department of shipping, Wuhan university of technology, Wuhan, 430063, China \\ ${ }^{4}$ Department of shipping, Wuhan university of technology, Wuhan, 430063, China \\ ${ }^{5}$ Department of computer science and technology, Wuhan university of technology, Wuhan, 430063 , \\ China \\ aemail: 984393738@qq.com, bemail: ljxteacher@sohu.com, cemail: 1424530724@qq.com \\ demail:734640487@qq.com, eemail:530453728@qq.com
}

Keywords: Interpretative Structural Modeling Method; Analytic Hierarchy Process; Multi-level Fuzzy Synthetic Evaluation Model; Sea Rescue Ability Evaluation

\begin{abstract}
In marine accident disposal, the maritime sector of sea area's rescue abilities evaluation plays an essential role in improving emergency rescue abilities as well as optimizing the management, which can reduce similar occurrings. In this paper, Interpretative Structural Modeling(ISM) was firstly used in analyzing the correlation between assessment indicators about marine rescue abilities. Then, through the Analytic Hierarchy Process(AHP) every indicator's weight was ascertained. Finally, we assessed the rescue abilities by multi-level fuzzy comprehensive evaluation. The results can embody the degree of excellence of marine rescue abilities in waters, specifically point out the existing problems and put forward relevant suggestion according to the order of importance to lower the loss of similar marine accidents. With regard to the rescue abilities of marine or onshore emergency, this paper's research is of great theoretical and practical value.
\end{abstract}

\section{Introduction}

With the maritime transport bringing economic value, marine accidents, however, have brought serious harm to the safety of life, property safety and the environment. After the accident, the rescue capacity of the maritime department near the accident spot plays a decisive role in reducing the loss. To improve the rescue ability at sea, we can obtain the degree of excellence by evaluation, combined with the importance ranking of rescue ability indicators, to point out the problems and put forward corresponding opinions. Then, the maritime sector is to take measures based on problems and opinions to improve the marine rescue ability and reduce the loss caused by similar accidents. At present, many international scholars or departments concerned have done a lot of research on the evaluation of competency, and have achieved some results. In China, scholars such as Yang Li, Wang Lei in the coal mine emergency rescue capacity evaluating indicator system based on ISM finally obtained the coal mine emergency rescue capability evaluating indicator system model diagram by establishing the adjacency matrix and reachability matrix among the evaluating indicators of coal mine emergency rescue capability, which provides a basis for evaluating the coal mine emergency rescue capability. For multi-purpose indicators, they can also be reflected through the model diagram system, which reduces the duplication of redundant targets and highlights the selected indicators of the necessity and comprehensiveness [1]. As another example, Hu Jun Feng and others in the research on evaluating indicators system of regional integrated disaster mitigation capability established an evaluating indicator system of regional integrated disaster mitigation 
capability, which can access the integrated disaster reduction capacity in a region and compare the capacity of numerical differences of a certain region in different periods [2]. FEMA and IAEM in the United States, jointly proposed the state and local government emergency response assessment system (CAR) in 1997. The system has 13 emergency management functions, each with corresponding evaluating indicators. What is more, each emergency management function is divided into several attributes, subdivided into several features respectively. Each state can assess its emergency response capability at the level of each attribute [3]. It can be seen that experts and relevant maritime institutions have had some research on disaster relief capability evaluation, but there is no mature solution for the evaluation of emergency rescue capability at sea. In allusion to the evaluation of marine rescue capability, this paper firstly uses ISM to analyze the relationship between the evaluating indicators of sea rescue capacity [4], and then determine the weight of each indicator through AHP [5]. Finally, it evaluates the rescue ability with multi-level fuzzy comprehensive evaluation. The evaluation results can be used to assess the maritime rescue ability of the maritime sector in a certain sea area, and point out the existing problems and propose corresponding opinions according to the importance ranking of the indicators to reduce the loss caused by similar accidents at sea. This program can effectively assess the rescue ability of the maritime sector with a good practicality.

\section{Evaluation Model of Maritime Rescue Ability}

\section{Rescue capability evaluation indicator system}

The evaluation indicator system of maritime rescue capability includes the indicators and their relationships.

\section{Maritime rescue capability indicators}

As is shown in Table 1, there are usually 23 indicators for assessing marine rescue abilities. Table1 Assessment indicators of marine rescue abilities

\begin{tabular}{cc}
\hline Assessment indicators & The indicator number $\mathrm{S}_{\mathrm{i}}$ \\
\hline Emergency rescue capability & $\mathrm{S}_{0}$ \\
Emergency response capability & $\mathrm{S}_{1}$ \\
Communication management & $\mathrm{S}_{2}$ \\
Resource guarantee & $\mathrm{S}_{3}$ \\
Aid decision making & $\mathrm{S}_{4}$ \\
Regulation and control & $\mathrm{S}_{5}$ \\
Emergency measures & $\mathrm{S}_{6}$ \\
Time-effect of dispatch & $\mathrm{S}_{7}$ \\
Personnel composition & $\mathrm{S}_{8}$ \\
Gathering & $\mathrm{S}_{9}$ \\
Equipment transfer & $\mathrm{S}_{10}$ \\
Salvage effect & $\mathrm{S}_{11}$ \\
First respond at the spot & $\mathrm{S}_{12}$ \\
Collection of transportation information & $\mathrm{S}_{13}$ \\
Information consolidation at the spot & $\mathrm{S}_{14}$ \\
Comprehensive consideration and evaluation of & $\mathrm{S}_{15}$ \\
risks and uncertain factors & \\
Rapid rescue plan making & $\mathrm{S}_{16}$ \\
Efficient allocation of rescue resources & $\mathrm{S}_{17}$ \\
Unified coordination and risk control in the & $\mathrm{S}_{18}$ \\
rescue process & $\mathrm{S}_{19}$ \\
Joint rescue & $\mathrm{S}_{20}$ \\
Command center & $\mathrm{S}_{21}$ \\
Relevant departments & $\mathrm{S}_{22}$ \\
Relevant local government &
\end{tabular}




\section{Confirmation of the correlation between assessment indicators}

After the assessment indicators determined, the correlation between the indicators needs to be confirmed. Interpretative Structural Modeling (ISM) is a structural modeling technique proposed by J Warfield [6]. The model can be used to better determine the relationship between the assessment indicators of marine rescue ability. The specific steps are as follows:

(1) Adjacency matrix building

The influences between the assessment indicators of marine rescue ability are described by the adjacency matrix $\mathrm{A}$. The element $\mathrm{a}_{\mathrm{ij}}$ in $\mathrm{A}$ is used to express the influence between the factors, as is shown in formula (1).

$$
a_{i j}= \begin{cases}1 & \left(S_{i} \text { is directly related to the } S_{j}\right) \\ 0 & \left(S_{i} \text { is not directly related to the } S_{j}\right)\end{cases}
$$

Through group discussing and research as well as expert consultant, we get the adjacency matrix A of the marine rescue ability indicators, as is shown in Table 2.

Table2 Adjacency matrix A

\begin{tabular}{|c|c|c|c|c|c|c|c|c|c|c|c|c|c|c|c|c|c|c|c|c|c|c|c|}
\hline & $\mathrm{S}_{0}$ & $S_{1}$ & $\mathrm{~S}_{2}$ & $\mathrm{~S}_{3}$ & $\mathrm{~S}_{4}$ & $\mathrm{~S}_{5}$ & $\mathrm{~S}_{6}$ & $\mathrm{~S}_{7}$ & $\mathrm{~S}_{8}$ & $\mathrm{~S}_{9}$ & $\mathrm{~S}_{10}$ & $S_{11}$ & $\mathrm{~S}_{12}$ & $\mathrm{~S}_{13}$ & $\mathrm{~S}_{14}$ & $\mathrm{~S}_{15}$ & $S_{16}$ & $\mathrm{~S}_{17}$ & $\mathrm{~S}_{18}$ & $\mathrm{~S}_{19}$ & $\mathrm{~S}_{20}$ & $\mathrm{~S}_{21}$ & $\mathrm{~S}_{22}$ \\
\hline $\mathrm{S}_{0}$ & 1 & 0 & 0 & 0 & 0 & 0 & 0 & 0 & 0 & 0 & 0 & 0 & 0 & 0 & 0 & 0 & 0 & 0 & 0 & 0 & 0 & 0 & 0 \\
\hline $\mathrm{S}_{1}$ & 1 & 1 & 0 & 0 & 0 & 0 & 0 & 0 & 0 & 0 & 0 & 0 & 0 & 0 & 0 & 0 & 0 & 0 & 0 & 0 & 0 & 0 & 0 \\
\hline $\mathrm{S}_{2}$ & 1 & 1 & 1 & 1 & 1 & 1 & 1 & 0 & 0 & 0 & 0 & 1 & 0 & 0 & 0 & 0 & 0 & 0 & 0 & 0 & 0 & 0 & 0 \\
\hline $\mathrm{S}_{3}$ & 1 & 1 & 0 & 1 & 1 & 1 & 1 & 0 & 0 & 0 & 0 & 0 & 0 & 0 & 0 & 0 & 0 & 1 & 0 & 0 & 0 & 0 & 0 \\
\hline $\mathrm{S}_{4}$ & 1 & 1 & 0 & 0 & 1 & 0 & 0 & 1 & 0 & 0 & 0 & 0 & 0 & 0 & 0 & 0 & 0 & 0 & 0 & 0 & 0 & 0 & 0 \\
\hline $\mathrm{S}_{5}$ & 1 & 1 & 0 & 0 & 0 & 1 & 0 & 1 & 1 & 0 & 0 & 0 & 0 & 0 & 0 & 0 & 0 & 0 & 0 & 0 & 0 & 0 & 0 \\
\hline $\mathrm{S}_{6}$ & 1 & 1 & 0 & 0 & 0 & 0 & 1 & 1 & 1 & 0 & 0 & 0 & 0 & 0 & 0 & 0 & 0 & 0 & 0 & 0 & 0 & 0 & 0 \\
\hline $\mathrm{S}_{7}$ & 1 & 0 & 0 & 0 & 0 & 0 & 0 & 1 & 0 & 0 & 0 & 0 & 0 & 0 & 0 & 0 & 0 & 0 & 0 & 0 & 0 & 0 & 0 \\
\hline $\mathrm{S}_{8}$ & 1 & 1 & 0 & 0 & 0 & 0 & 0 & 1 & 1 & 0 & 0 & 0 & 1 & 0 & 0 & 0 & 0 & 0 & 0 & 0 & 0 & 0 & 0 \\
\hline $\mathrm{S}_{9}$ & 1 & 1 & 0 & 0 & 0 & 0 & 0 & 1 & 0 & 1 & 0 & 0 & 1 & 0 & 0 & 0 & 0 & 0 & 0 & 0 & 0 & 0 & 0 \\
\hline$S_{10}$ & 1 & 1 & 0 & 0 & 0 & 0 & 0 & 1 & 0 & 0 & 1 & 0 & 1 & 0 & 0 & 0 & 0 & 0 & 0 & 0 & 0 & 0 & 0 \\
\hline$S_{11}$ & 1 & 0 & 0 & 0 & 0 & 0 & 0 & 1 & 0 & 0 & 0 & 1 & 1 & 0 & 0 & 0 & 0 & 0 & 0 & 0 & 0 & 0 & 0 \\
\hline$\underline{S_{12}}$ & 1 & 0 & 0 & 0 & 0 & 0 & 0 & 0 & 0 & 0 & 0 & 0 & 1 & 0 & 0 & 0 & 0 & 0 & 0 & 0 & 0 & 0 & 0 \\
\hline$S_{13}$ & 1 & 1 & 0 & 0 & 0 & 0 & 0 & 0 & 0 & 0 & 0 & 0 & 1 & 1 & 0 & 0 & 0 & 0 & 0 & 0 & 0 & 0 & 0 \\
\hline $\mathrm{S}_{14}$ & 1 & 0 & 0 & 0 & 0 & 0 & 0 & 0 & 0 & 0 & 0 & 0 & 1 & 0 & 1 & 1 & 1 & 0 & 0 & 0 & 0 & 0 & 0 \\
\hline$S_{15}$ & 1 & 0 & 0 & 0 & 0 & 0 & 0 & 0 & 0 & 0 & 0 & 0 & 1 & 0 & 0 & 1 & 1 & 0 & 1 & 0 & 0 & 0 & 0 \\
\hline$S_{16}$ & 1 & 1 & 0 & 0 & 0 & 0 & 0 & 0 & 0 & 0 & 0 & 0 & 1 & 0 & 0 & 0 & 1 & 0 & 0 & 0 & 0 & 0 & 0 \\
\hline$S_{17}$ & 1 & 1 & 0 & 0 & 0 & 0 & 0 & 0 & 0 & 0 & 0 & 0 & 1 & 0 & 0 & 0 & 0 & 1 & 0 & 0 & 0 & 0 & 0 \\
\hline $\mathrm{S}_{18}$ & 1 & 0 & 0 & 0 & 0 & 0 & 0 & 0 & 0 & 0 & 0 & 0 & 1 & 0 & 0 & 0 & 0 & 0 & 1 & 0 & 0 & 0 & 0 \\
\hline $\mathrm{S}_{19}$ & 1 & 0 & 0 & 0 & 0 & 0 & 0 & 0 & 0 & 0 & 0 & 0 & 0 & 0 & 0 & 0 & 0 & 0 & 0 & 1 & 0 & 0 & 0 \\
\hline $\mathrm{S}_{20}$ & 1 & 1 & 0 & 0 & 0 & 1 & 0 & 1 & 1 & 0 & 0 & 0 & 0 & 0 & 0 & 0 & 1 & 1 & 1 & 1 & 1 & 1 & 1 \\
\hline $\mathrm{S}_{21}$ & 1 & 1 & 0 & 0 & 1 & 1 & 0 & 1 & 1 & 0 & 0 & 0 & 0 & 0 & 0 & 0 & 1 & 1 & 1 & 1 & 1 & 1 & 1 \\
\hline $\mathrm{S}_{22}$ & 1 & 1 & 0 & 0 & 1 & 1 & 0 & 1 & 1 & 0 & 0 & 0 & 0 & 0 & 0 & 0 & 1 & 1 & 1 & 1 & 1 & 1 & 1 \\
\hline
\end{tabular}

(2) Reachable matrix building

The degree to which a certain path through each node in a directed graph can be reached is described by the reachable matrix M. Since the adjacency matrix A belongs to the Boolean matrix, we use the Boolean matrix algorithm to calculate the reachable matrix:

$$
M=(A+I)^{k}=(A+I)^{(k-1)} \neq(A+I)^{(k-2)} \neq \cdot \cdot(A+I) \quad(k \leq n-1)
$$

The reachability matrix $M$ represents all the direct and indirect relationships between each of the rescue ability indicators.

\section{(3) Hierarchy chart building}

In the reachable matrix $M$, we establish the reachable set $\mathrm{R}\left(\mathrm{S}_{\mathrm{i}}\right)$, which means that the indicator $\mathrm{S}_{\mathrm{i}}$ can reach all the indicators of the set, then sum up the direct impact of the indicators; $\mathrm{A}\left(\mathrm{S}_{\mathrm{i}}\right)$ denotes the set of all indicators that can reach the index $S_{i}$, and sums up the affected relationship 
among the indicators; Let $C\left(S_{i}\right)=R\left(S_{i}\right) \cap A\left(S_{i}\right)$ represent the indicator having interference with $\mathrm{S}_{\mathrm{i}}$. The $\mathrm{R}\left(\mathrm{S}_{\mathrm{i}}\right), \mathrm{A}\left(\mathrm{S}_{\mathrm{i}}\right)$ and $\mathrm{C}\left(\mathrm{S}_{\mathrm{i}}\right)$ of the reachable matrix $\mathrm{M}$ are shown in Table 3. Table3 $\mathrm{R}(\mathrm{Si}) 、 \mathrm{~A}(\mathrm{Si})$ and $\mathrm{C}(\mathrm{Si})$ of reachable matrix $\mathrm{M}$

\begin{tabular}{cccc}
\hline $\mathrm{S}_{\mathrm{i}}$ & $\mathrm{R}\left(\mathrm{S}_{\mathrm{i}}\right)$ & $\mathrm{A}\left(\mathrm{S}_{\mathrm{i}}\right)$ & $\mathrm{C}\left(\mathrm{S}_{\mathrm{i}}\right)$ \\
\hline 0 & 0 & $\mathrm{All}$ included & 0 \\
1 & 0,1 & $1,2,3,4,5,6,8,9,10,13,14,15,16,17,20,21,22$ & 1 \\
2 & $0,1,2,3,4,5,6,7,8,11,12,17$ & 2 & 2 \\
3 & $0,1,3,4,5,6,7,8,12,17$ & 2,3 & 3 \\
4 & $0,1,4,7$ & $2,3,4,20,21,22$ & 4 \\
5 & $0,1,5,7,8,12$ & $2,3,5,20,21,22$ & 5 \\
6 & $0,1,6,7,8,12$ & $2,3,6$ & 6 \\
7 & 0,7 & $2,3,4,5,6,7,8,9,10,11,20,21,22$ & 7 \\
8 & $0,1,7,8,12$ & $2,3,5,6,8,20,21,22$ & 9 \\
9 & $0,1,7,9,12$ & 9 & 9 \\
10 & $0,1,7,10,12$ & 10 & 10 \\
11 & $0,7,11,12$ & 2,11 & 11 \\
12 & 0,12 & 13 & 12 \\
13 & $0,1,12,13$ & 14 & 13 \\
14 & $0,1,12,14,15,16,18$ & 14,15 & 14 \\
15 & $0,1,12,15,16,18$ & $14,15,16,20,21,22$ & 15 \\
16 & $0,1,12,16$ & $2,4,17,20,21,22$ & 16 \\
17 & $0,1,12,17$ & $14,15,18,20,21,22$ & 17 \\
18 & $0,12,18$ & $19,20,21,22$ & 18 \\
19 & 0,19 & $20,21,22$ & 19 \\
20 & $0,1,4,5,7,8,12,16,17,18,19,20,21,22$ & $20,21,22$ & $2,3,5,6,8,9,10,11,12,13,14,15,16,17,18,20,21,22$ \\
21 & $0,1,4,5,7,8,12,16,17,18,19,20,21,22$ & $20,21,22$ & 21 \\
22 & $0,1,4,5,7,8,12,16,17,18,19,20,21,22$ & 22 & \\
\hline
\end{tabular}

After the highest-level indicator elements set confirmed, we remove the corresponding rows and columns in the matrix, and then seek the new highest-level elements from the remaining. And so on, the highest-level elements set included in each level are able to be found [7]. Results:
$\mathrm{L} 1=\left\{\mathrm{S}_{0}\right\}$
(3) $\mathrm{L} 2=\left\{\mathrm{S}_{1}, \mathrm{~S}_{7}, \mathrm{~S}_{12}, \mathrm{~S}_{19}\right\}$
$\mathrm{L} 3=\left\{\mathrm{S}_{4}, \mathrm{~S}_{8}, \mathrm{~S}_{9}, \mathrm{~S}_{10}, \mathrm{~S}_{11}, \mathrm{~S}_{13}, \mathrm{~S}_{16}, \mathrm{~S}_{17}, \mathrm{~S}_{18}\right\}$
(5) $\mathrm{L} 4=\left\{\mathrm{S}_{5}, \mathrm{~S}_{6}, \mathrm{~S}_{15}\right\}$
$\mathrm{L} 5=\left\{\mathrm{S}_{3}, \mathrm{~S}_{14}, \mathrm{~S}_{20}, \mathrm{~S}_{21}, \mathrm{~S}_{22}\right\}$
(7) $\mathrm{L} 6=\left\{\mathrm{S}_{2}\right\}$

According to the classification of $\mathrm{Li}$, confirm the connection between the higher level indicators and the lower level indicators combined with reachable matrix, so as to establish the interpretive structural model of marine emergency response abilities assessment indicators in Figure 1.

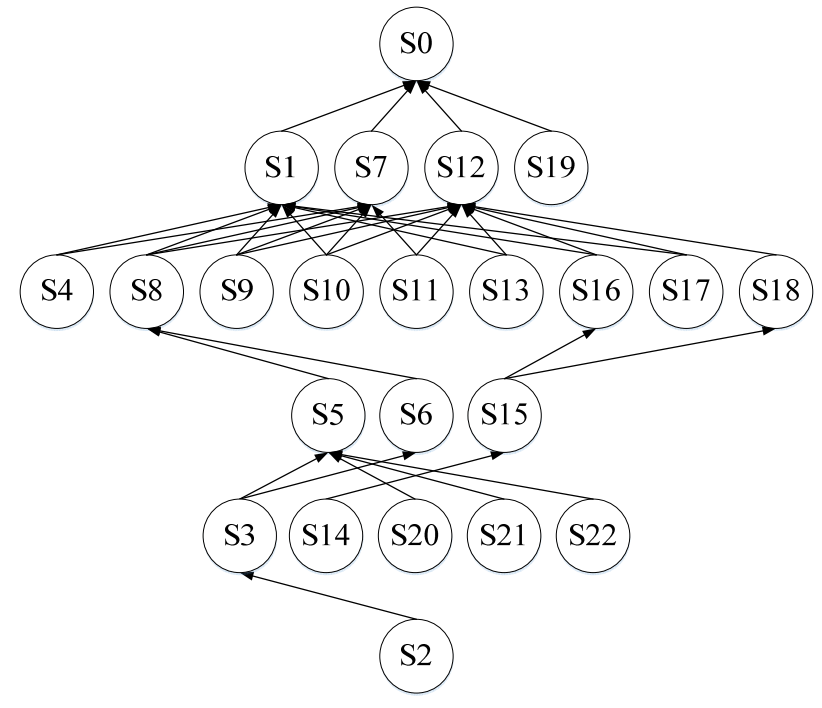

Fig.1 Interpretive structural model of marine emergency response abilities assessment indicators

\section{Analysis of the impact of emergency rescue ability indicators}

To improve relatively important indicators, is an important approach to quickly and effectively improve the ability of emergency rescue at sea [8]. Because of the large number of emergency rescue ability indicators, the AHP method is used to rank the important indicators, and then we can 
identify and select the indicators that have a greater impact on the emergency rescue ability. AHP is a systematic engineering method proposed by T. L. Saaty in the 1970s. It combines people's subjective judgment to transfer qualitative analysis into quantitative analysis, thus simplifying the complex system, making it into the paired comparison and simple calculations.

\section{Pairwise comparison matrix building}

According to the indicator system using ISM, the relative importance of peer indicators is compared by expert scoring. As Table 4 depicts, $\mathrm{S}_{\mathrm{i}, \mathrm{j}}$ represents the importance of indicator $\mathrm{S}_{\mathrm{i}}$ relative to $S_{j}$, the value in accordance with scale 1 to 9 . On this basis, we establish the judgment matrix. The first and seventh indicators are not compared for being individual indicators with weight set to 1 . Table 5 (a) - (d) shows the pairwise comparison matrix of the secondary to fifth class indicators.

\begin{tabular}{ll}
\hline $\mathrm{S}_{\mathrm{i}, \mathrm{j}}$ & Interpretation \\
\hline 1 & $\mathrm{~S}_{\mathrm{i}}, \mathrm{S}_{\mathrm{j}}$ are of equal importance \\
3 & Compared with $\mathrm{S}_{\mathrm{j}}, \mathrm{S}_{\mathrm{i}}$ is of weak importance \\
5 & Compared with $\mathrm{S}_{\mathrm{j}}, \mathrm{S}_{\mathrm{i}}$ is of strong importance \\
7 & Compared with $\mathrm{S}_{\mathrm{j}}, \mathrm{S}_{\mathrm{i}}$ is of very strong \\
9 & importance \\
\hline
\end{tabular}

(Note: $2,4,6,8$, respectively represents the mid-value of the two adjacent standard values.)

Table4 Relative importance of indicators at the same level

\begin{tabular}{|c|c|c|c|c|}
\hline & $\mathrm{S}_{1}$ & $\mathrm{~S}_{7}$ & $\mathrm{~S}_{12}$ & $\mathrm{~S}_{19}$ \\
\hline $\mathrm{S}_{1}$ & 1 & $1 / 2$ & 1 & 3 \\
\hline $\mathrm{S}_{7}$ & 2 & 1 & 1 & 5 \\
\hline $\mathrm{S}_{12}$ & 2 & 1 & 1 & 5 \\
\hline $\mathrm{S}_{19}$ & $1 / 3$ & $1 / 5$ & $1 / 5$ & 1 \\
\hline
\end{tabular}

Table5 (a)

\begin{tabular}{|c|c|c|c|c|c|c|c|c|c|}
\hline & $\mathrm{S}_{4}$ & $\mathrm{~S}_{8}$ & $\mathrm{~S}_{9}$ & $\mathrm{~S}_{10}$ & $\mathrm{~S}_{11}$ & $\mathrm{~S}_{13}$ & $\mathrm{~S}_{16}$ & $\mathrm{~S}_{17}$ & $\mathrm{~S}_{18}$ \\
\hline $\mathrm{S}_{4}$ & 1 & $1 / 2$ & $1 / 5$ & $1 / 5$ & 2 & $1 / 5$ & $1 / 3$ & 2 & 1 \\
\hline $\mathrm{S}_{8}$ & 2 & 1 & $1 / 2$ & $1 / 2$ & 4 & 2 & 1 & 4 & 2 \\
\hline $\mathrm{S}_{9}$ & 5 & $1 / 2$ & 1 & 1 & 9 & 1 & 2 & 8 & 5 \\
\hline $\mathrm{S}_{10}$ & 5 & $1 / 2$ & 1 & 1 & 9 & 1 & 2 & 9 & 6 \\
\hline $\mathrm{S}_{11}$ & $1 / 2$ & $1 / 4$ & $1 / 9$ & $1 / 9$ & 1 & $1 / 9$ & $1 / 6$ & 1 & $1 / 2$ \\
\hline $\mathrm{S}_{13}$ & 5 & $1 / 2$ & 1 & 1 & 9 & 1 & 2 & 9 & 5 \\
\hline $\mathrm{S}_{16}$ & 3 & $1 / 2$ & $1 / 2$ & $1 / 2$ & 6 & $1 / 2$ & 1 & 5 & 3 \\
\hline $\mathrm{S}_{17}$ & $1 / 2$ & $1 / 4$ & $1 / 9$ & $1 / 9$ & 1 & $1 / 9$ & $1 / 5$ & 1 & $1 / 3$ \\
\hline $\mathrm{S}_{18}$ & 1 & $1 / 2$ & $1 / 5$ & $1 / 6$ & 2 & $1 / 5$ & $1 / 3$ & 3 & 1 \\
\hline
\end{tabular}

Table5 (b)

\begin{tabular}{|c|c|c|c|}
\hline & $\mathrm{S}_{5}$ & $\mathrm{~S}_{6}$ & $\mathrm{~S}_{15}$ \\
\hline $\mathrm{S}_{5}$ & 1 & 5 & 2 \\
\hline $\mathrm{S}_{6}$ & $1 / 5$ & 1 & $1 / 3$ \\
\hline $\mathrm{S}_{15}$ & $1 / 2$ & 3 & 1 \\
\hline
\end{tabular}

Table5 (c)

\begin{tabular}{|c|c|c|c|c|c|}
\hline & $\mathrm{S}_{3}$ & $\mathrm{~S}_{14}$ & $\mathrm{~S}_{20}$ & $\mathrm{~S}_{21}$ & $\mathrm{~S}_{22}$ \\
\hline $\mathrm{S}_{3}$ & 1 & 2 & $1 / 3$ & $1 / 2$ & 2 \\
\hline $\mathrm{S}_{14}$ & $1 / 2$ & 1 & $1 / 9$ & $1 / 5$ & 1 \\
\hline $\mathrm{S}_{20}$ & 3 & 9 & 1 & 2 & 6 \\
\hline $\mathrm{S}_{21}$ & 2 & 5 & $1 / 2$ & 1 & 5 \\
\hline $\mathrm{S}_{22}$ & $1 / 2$ & 1 & $1 / 6$ & $1 / 5$ & 1 \\
\hline
\end{tabular}

Table5 (d)

Table5 Pairwise comparison matrix of indicators at different levels 


\section{Weight calculation}

Calculate the eigenvectors of each grade in pairwise comparison matrix, and normalize to get weight vector $\mathrm{Wi}=(\mathrm{W} 1, \mathrm{~W} 2, \ldots, \mathrm{Wn}), \mathrm{Wn}$, the weight corresponding to indicator $\mathrm{n}$. Check consistency. If the random conformance rate $\mathrm{CR} \leqq 0.1$, then the consistency check is passed. The weights at different levels confirmed are as follows:

Second class indicator: the largest eigenvalue $X=4.23078$, coincidence indicator $C I=0.07693$, random conformance rate $\mathrm{CR}=0.08643<0.1$, pass the consistency check. Weight vector $\mathrm{W} 2=$ $\left(\begin{array}{llll}0.2109 & 0.3388 & 0.3388 & 0.0647\end{array}\right)$.

Third class indicator: the largest eigenvalue $X=9.04844$, coincidence indicator $C I=0.00606$, random conformance rate $\mathrm{CR}=0.00415<0.1$, pass the consistency check. Weight vector $\mathrm{W} 3=$
( 0.0070
0.0555
0.1520
0.1639
$0.0014 \quad 0.15660 .0473$
0.0014
0.0067).

Fourth class indicator: the largest eigenvalue $X=3.00369$, coincidence indicator $C I=0.00185$, random conformance rate $\mathrm{CR}=0.00355<0.1$, pass the consistency check. Weight vector $\mathrm{W} 4=$ $\left(\begin{array}{lll}0.5179 & 0.1480 & 0.3223\end{array}\right)$.

Fifth class indicator: the largest eigenvalue $X=5.03142$, coincidence indicator $\mathrm{CI}=0.00785$, random conformance rate $\mathrm{CR}=0.00701<0.1$, pass the consistency check. Weight vector W5= $\left(\begin{array}{lllll}0.1181 & 0.0424 & 0.5544 & 0.2922 & 0.0470\end{array}\right)$.

\section{Multi-level fuzzy comprehensive evaluation}

The decision-making and rescue of emergency rescue at sea involves the influence of multiple indicators and the coordination assistance of multiple departments, which is a complex fuzzy system. With indicators classified, it is possible to build a multi-level fuzzy comprehensive evaluation model based on the structural model using the ISM and the indicator weight obtained by the AHP. The model can be applied to the evaluation of the rescue capability of a marine emergency rescue unit.

\section{Basic principle of fuzzy comprehensive evaluation}

Suppose the set of evaluation indicators is U, establish a multi-level indicator set based on the structure model:
$U=\left\{U_{1}\left(S_{1}, S_{7}, S_{12}, S_{19}\right)\right\}$
(9) $U=\left\{U_{1}\left(S_{4}, S_{8}, S_{9}, S_{10}, S_{11}, S_{13}, S_{16}, S_{17}, S_{18}\right)\right\}$
$U=\left\{U_{1}\left(S_{5}, S_{6}, S_{5}\right)\right\}$
(11) $U=\left\{U_{1}\left(S_{3}, S_{14}, S_{20}, S_{21}, S_{22}\right)\right\}$

Establish a goal set of marine emergency rescue ability indicators [9]:

$\mathrm{V}=\{$ Excellent Good Average Up to the standard Poor $\}$

Excellent represents that the indicator can dramatically improve marine emergency rescue ability. And so forth, poor represents that the indicator deteriorate emergency ability.

According to the evaluation indicator system of marine emergency rescue ability, the weight of each indicator is determined by AHP, the multi-level fuzzy evaluation model is established with the membership function, and the emergency rescue capability of a specific marine emergency rescue unit is evaluated synthetically. The synthetic algorithm of fuzzy comprehensive evaluation is shown as formula (13):

$$
B=W \circ R
$$

In the formula: $\mathrm{W}$ is the weight vector of the weights of the evaluation indicators of the marine emergency rescue ability determined by the AHP; $\mathrm{R}$ is the fuzzy relation matrix; B denotes the fuzzy comprehensive evaluation matrix of the grade; “०” is synthesis operator, take $M(\bullet, \oplus):: \bullet$ is defined as $a \bullet b=a \times b=a b ; \oplus$ is defined as $a \oplus b=(a+b) \wedge 1$.

The final evaluation matrix of the fuzzy comprehensive evaluation model is obtained by evaluating each indicator according to the goal. According to the principle of maximum degree of membership, the evaluation grade of maximum membership in fuzzy comprehensive evaluation matrix is the final evaluation result. 


\section{The Determination of membership of each indicator}

The goal set of a certain indicator is described by the membership function. Since the index set of comments is divided into five levels, meanwhile taking into account the way of marking, the isosceles triangle membership function is adopted. The mathematical description of the membership of ith indicator is shown in (14).

$$
r_{i}\left(v_{k}\right)=\left\{\begin{array}{lc}
\frac{s_{i}-m_{k}}{n_{k}-m_{k}}, & m_{k} \leq s_{i} \leq n_{k} \\
\frac{p_{k}-s_{i}}{s_{i}-n_{k}}, & n_{k} \leq s_{i} \leq h_{k} \\
0, & \text { other }
\end{array}\right.
$$

In the formula: $\mathrm{mk}, \mathrm{nk}, \mathrm{pk}$ is the constant corresponding to $\mathrm{k}$-th evaluation level. The standardized indicators are corresponding to the goals: $n_{1}=0, n_{2}=0.25, n_{3}=0.5, n_{4}=0.75, n_{5}=1$. To ensure that each indicator can get at least four reviews of membership, take the base of isosceles triangle of 1.6. Thus the five membership functions are as follows:

$$
\begin{gathered}
r_{i}\left(v_{1}\right)=\left\{\begin{array}{lc}
\frac{s_{i}-0.2}{0.8}, & 0.2 \leq s_{i} \leq 1 \\
0, & \text { other }
\end{array}\right. \\
r_{i}\left(v_{3}\right)= \begin{cases}\frac{s_{i}+0.3}{0.8}, & 0 \leq s_{i} \leq 0.5 \\
\frac{1.3-s_{i}}{0.8}, & 0.5 \leq s_{i} \leq 1\end{cases} \\
r_{i}\left(v_{5}\right)= \begin{cases}\frac{0.8-s_{i}}{0.8}, & (15) \\
0, & 0 \leq s_{i} \leq 0.8\end{cases}
\end{gathered}
$$

Therefore, the fuzzy relation matrix $R_{q}$ of level q is shown as formula (20).

$$
R_{q}=\left[\begin{array}{cccc}
r_{11} & r_{12} & \cdots & r_{1 n} \\
r_{21} & r_{22} & \cdots & r_{2 n} \\
\vdots & \vdots & & \vdots \\
r_{n 1} & r_{n 2} & \cdots & r_{n n}
\end{array}\right]
$$

\section{Comprehensive evaluation result of marine emergency rescue ability}

After the membership of each index determined, based on the basic principle of multi-level fuzzy comprehensive evaluation, the comprehensive evaluation result of the marine emergency rescue ability is shown in formula (21).

$$
B=W \circ R=\left(w_{2}, w_{3}, w_{4}, w_{5}, w_{6}\right) \circ\left(\begin{array}{l}
W_{2} \circ R_{2} \\
W_{3} \circ R_{3} \\
W_{4} \circ R_{4} \\
W_{5} \circ R_{5} \\
W_{6} \circ R_{6}
\end{array}\right)=\left(b_{2}, b_{3}, b_{4}, b_{5}, b_{6}\right)
$$

In the formula: the weight of each level calculated by AHP is: $w_{2}, w_{3}, w_{4}, w_{5}, w_{6}=0.4418,0.2351$, $0.1509,0.0900, \quad 0.0822, \quad \mathrm{CR}=0.0086$.

\section{Case analysis}

Taking the assessment of marine emergency rescue abilities of an emergency rescue department in Bohai Bay as an example, the experts' scoring method was used to score the emergency rescue abilities evaluation indicators of the department. Score interval is set to $1-100$, the higher the score the better the indicator. The specific scores are shown in Table 6. 
Table6 Indicators scoring about the emergency rescue abilities assessment

\begin{tabular}{cc}
\hline Assessment indicators & Score \\
\hline Emergency response capability $\mathrm{S}_{1}$ & 81 \\
Communication management $\mathrm{S}_{2}$ & 91 \\
Resource guarantee $\mathrm{S}_{3}$ & 13 \\
Aid decision making $\mathrm{S}_{4}$ & 91 \\
Regulation and control $\mathrm{S}_{5}$ & 63 \\
Emergency measures $\mathrm{S}_{6}$ & 10 \\
Time-effect of dispatch $\mathrm{S}_{7}$ & 28 \\
Personnel composition $\mathrm{S}_{8}$ & 55 \\
Gathering $\mathrm{S}_{9}$ & 96 \\
Equipment transfer $\mathrm{S}_{10}$ & 96 \\
Salvage effect $\mathrm{S}_{12}$ & 16 \\
First respond at the spot $\mathrm{S}_{13}$ & 97 \\
Collection of transportation information $\mathrm{S}_{11}$ & 96 \\
Information consolidation at the spot $\mathrm{S}_{14}$ & 49 \\
Comprehensive consideration and evaluation of & 80 \\
risks and uncertain factors $\mathrm{S}_{15}$ & 14 \\
Rapid rescue plan making $\mathrm{S}_{16}$ & 42 \\
Efficient allocation of rescue resources $\mathrm{S}_{17}$ & 92 \\
Unified coordination and risk control in the & 79 \\
rescue process $\mathrm{S}_{18}$ & 96 \\
Joint rescue $\mathrm{S}_{19}$ & 66 \\
Command center $\mathrm{S}_{20}$ & 4 \\
Relevant departments $\mathrm{S}_{21}$ & \\
Relevant local government $\mathrm{S}_{22}$ &
\end{tabular}

The scores of indicators of each level are normalized by min-max method, and the standardized evaluation matrix is obtained as shown in formula (22) - (27).

$$
\begin{aligned}
& C_{i j}^{\prime}=\frac{C_{i j}-C_{i \max }}{C_{i \max }-C_{i \min }} \\
& C_{2}^{\prime}=\left[\begin{array}{llll}
0.77 & 0 & 1 & 0.74
\end{array}\right] \\
& C_{3}^{\prime}=\left[\begin{array}{lllllllll}
0.94 & 0.50 & 1.00 & 1.00 & 0.02 & 1 & 0 & 0.34 & 0.95
\end{array}\right] \\
& C_{4}^{\prime}=\left[\begin{array}{lll}
0.76 & 0 & 1
\end{array}\right] \\
& C_{s}^{\prime}=\left[\begin{array}{lllll}
0.10 & 0.49 & 1 & 0.67 & 0
\end{array}\right] \\
& C_{6}^{\prime}=[1]
\end{aligned}
$$

In the formula: $C_{i j}$ represents the jth indicator in level $\mathrm{i}, C_{i \min }, C_{i \max }$ represent the lowest score and highest score in level i. According to (15) - (19), the fuzzy evaluation matrix $\mathrm{R}_{\mathrm{i}}$ of indicator of each level is shown as (28) - (32).

$$
\begin{aligned}
R_{2}=\left[\begin{array}{lllll}
0.71 & 0.98 & 0.66 & 0.35 & 0.04 \\
0.00 & 0.06 & 0.38 & 0.69 & 1.00 \\
1.00 & 0.69 & 0.38 & 0.06 & 0.00 \\
0.68 & 0.93 & 0.70 & 0.39 & 0.08
\end{array}\right] & R_{3}=\left[\begin{array}{llllll}
0.92 & 0.76 & 0.45 & 0.14 & 0.00 \\
0.38 & 0.69 & 1.00 & 0.69 & 0.38 \\
1.00 & 0.69 & 0.38 & 0.06 & 0.00 \\
1.00 & 0.69 & 0.38 & 0.06 & 0.00 \\
0.00 & 0.09 & 0.41 & 0.72 & 0.97 \\
1.00 & 0.69 & 0.38 & 0.06 & 0.00 \\
0.00 & 0.06 & 0.38 & 0.69 & 1.00 \\
0.18 & 0.49 & 0.80 & 0.89 & 0.57 \\
0.94 & 0.75 & 0.44 & 0.12 & 0.00
\end{array}\right] \\
R_{4}= & (28) \\
{\left[\begin{array}{lllll}
0.70 & 1.00 & 0.68 & 0.37 & 0.05 \\
0.00 & 0.06 & 0.38 & 0.69 & 1.00 \\
1.00 & 0.69 & 0.38 & 0.06 & 0.00
\end{array}\right] \quad(30) } & R_{5}=\left[\begin{array}{llllll}
0.00 & 0.18 & 0.50 & 0.81 & 0.88 \\
0.36 & 0.67 & 0.99 & 0.70 & 0.39 \\
1.00 & 0.69 & 0.38 & 0.06 & 0.00 \\
0.59 & 0.90 & 0.78 & 0.47 & 0.16 \\
0.00 & 0.06 & 0.38 & 0.69 & 1.00
\end{array}\right]
\end{aligned}
$$

On the basis of AHP, we obtain the index weighting vector and the rank weighting vector. Fuzzy 
computing according to (15) - (21):

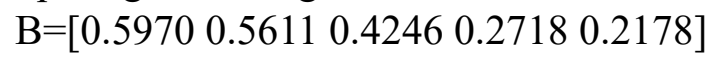

It is seen that the salvage capability of the marine emergency rescue unit is excellent for taking timely and appropriate rescue operations to meet most of the emergency rescue requirements. For further optimization, the indicator is to be analyzed step by step according to the structural model obtained by ISM and the importance ranking of the indicators obtained by AHP, improved targeted. First, we analyze the second class indicator. From Table 3 we see that the time-effect of dispatch is poor. Its corresponding subordinate indicators personnel composition and collection of transportation information are poor. By further analysis of subordinate indicators, we see the corresponding indicators regulation and control as well as emergency measures are poor. Corresponding indicator resource guarantee and relevant local government are poor. In conclusion, the department can improve cooperation with local departments, allocate the rescue personnel reasonably, and enhance the ability of transportation information collection, so as to effectively reduce the dispatch time, enhance efficiency and improve its rescue ability.

\section{Conclusions}

The degree of excellence is got through the evaluation of maritime rescue ability. Next, combined with the importance ranking of the rescue to point out the problems and make corresponding comments. On this basis, the maritime sector is able to take corresponding measures which can greatly improve the marine rescue ability to reduce the loss caused by accidents. For marine rescue ability evaluation, in this paper, we first use ISM to analyze the interaction between the assessment indicators of maritime rescue ability, and then determine the weight vector of each indicator by AHP, then use multi-level fuzzy evaluation to evaluate the rescue ability [10]. The evaluation results can reflect the degree of excellence of marine rescue ability of a certain maritime department. In order to verify the practicability of this model, we take the evaluation of marine rescue ability in a certain area of Bohai Bay as an example to analyze. The results prove that the model can effectively assess the excellence degree of marine rescue ability with good practicability. The model constructed in this project has reference significance for other similar ability evaluation problems.

\section{Acknowledgement}

In this paper, the research was sponsored by the National Undergraduate Training Program for Innovation and Entrepreneurship (Project No. 20161049712003).

\section{References}

[1] Li Yang, Lei Wang. Assessment Index System of Coal Mine Emergency Rescue Ability Based on Interpretative Structural Modeling Method [J]. Journal of China University of Mining \& Technology(Social Science) .2015(01)

[2] Junfeng Hu, Peiguo Yang. Regional Comprehensive Evaluation Index System of Disaster Reduction Capacity Based on ISM [J]. Journal of Catastrophology. 2014(01)

[3] Qingwen Tan. Maritime Emergency Response Management System [D]. Wuhan University of Technology.2010

[4] Chengcheng Liu. Methodology and Application of Coal Mine Emergency Rescue Capability Evaluation [D]. Anhui University Of Science \& Technology.2013

[5] Qingjuan Wang. The Path Optimization and Evaluation of HAZMAT Road Transportation Emergency Rescue System [D]. Chongqing Jiaotong University.2012

[6] Lili Jiang, Rui Wang. On Application of ISM in Improving Students'Learning Motives at 
Vocational Colleges [J]. Journal of Tourism College of Zhejiang.2012(01)

[7] Xufeng Zhang, Dan Zhu. ISM-based Analysis of Influence Factors of Basic Distribution Network Structure [J]. Logistics technology.2010(20)

[8] Wen Du. Research on the Rescue System of Catastrophic Emergency [D]. Henan University of Technology.2012

[9] Yi Cao. Synthetic Evaluation and Application Research on the Capability of Seismic Rescue Brigade [D]. National University of Defense Technology.2008

[10] Lei Li. Mechanical Material Selection Based on FAHP [J]. Modular Machine Tool \& Automatic Manufacturing Technique.2015(11) 